\title{
Prevention of delirium in trauma patients: Are we giving thiamine prophylaxis a fair chance?
}

\author{
Christopher Blackmore, $\mathrm{MD}^{*}+$ \\ Jean-Francois Ouellet, MD*+ \\ Daniel Niven, $\mathrm{MD}^{\ddagger}$ \\ Andrew W. Kirkpatrick, MD*† \\ Chad G. Ball, MD*ं
}

From the *Regional Trauma Services, †Department of Surgery, and ¥Department of Critical Care Medicine, University of Calgary, Foothills Medical Centre, Calgary, Alta.

This manuscript was presented in oral format at the Trauma Association of Canada Annual Meeting in Toronto, Ont. on Apr. 12, 2012.

Accepted for publication

Feb. 28, 2013

\section{Correspondence to:}

C.G. Ball

University of Calgary

Foothills Medical Centre

1403-29 St. NW

Calgary AB T2N 2T9

ball.chad@gmail.com

DOI: 10.1503/cjs.020112

\begin{abstract}
Background: Delirium is associated with increased morbidity and mortality in injured patients. Wernicke encephalopathy (WE) is delirium linked to malnutrition and chronic alcoholism. It is prevented with administration of thiamine. Our primary goal was to evaluate current blood alcohol level (BAL) testing and thiamine prophylaxis in severely injured patients.
\end{abstract}

Methods: We retrospectively reviewed the cases of 1000 consecutive severely injured patients admitted to hospital between Mar. 1, 2009, and Dec. 31, 2009. We used the patients' medical records and the Alberta Trauma Registry.

Results: Among 1000 patients (mean age $48 \mathrm{yr}$, male sex $70 \%$, mean injury severity score 23 , mortality 10\%), 627 underwent BAL testing at admission; 221 (35\%) had a BAL greater than $0 \mathrm{mmol} / \mathrm{L}$, and $189(30 \%)$ had a BAL above the legal limit of $17.4 \mathrm{mmol} / \mathrm{L}$. The mean positive BAL was $41.9 \mathrm{mmol} / \mathrm{L}$. More than $4 \%$ had a known history of alcohol abuse. More patients were assaulted (20\% v. $9 \%$ ) or hit by motor vehicles $(10 \%$ v. $6 \%$ ) when intoxicated (both $p<0.05)$. Most injuries occurred after falls $(37 \%)$ and motor vehicle collisions (33\%). Overall, $17 \%$ of patients received thiamine prophylaxis. Of the 221 patients with elevated BAL, $44 \%$ received thiamine prophylaxis. Of those with a history of alcohol abuse, $77 \%$ received thiamine prophylaxis.

Conclusion: Despite the strong link between alcohol abuse, trauma and WE, more than one-third of patients were not screened for alcohol use. Furthermore, a minority of intoxicated patients received adequate prophylaxis against WE. Given the low risk and cost of BAL testing and thiamine prophylaxis and the high cost of delirium, standard protocols for prophylaxis are essential.

Contexte : Le délire est associé à une morbidité et une mortalité accrues chez les traumatisés. L'encéphalopathie de Wernicke $(\mathrm{EW})$ est un délire associé à la malnutrition et à l'alcoolisme chronique que l'on peut prévenir en administrant de la thiamine. Notre objectif principal était d'évaluer le recours actuel aux tests d'alcoolémie et au traitement prophylactique à la thiamine chez les grands traumatisés.

Méthodes : Nous avons passé en revue de manière rétrospective 1000 cas consécutifs d'hospitalisation pour traumatismes graves entre le 1er mars 2009 et le 31 décembre 2009. Nous avons utilisé les dossiers médicaux des patients et le Registre des traumatismes de l'Alberta.

Résultats : Sur 1000 patients (âge moyen 48 ans, sexe masculin 70 \%, indice moyen de gravité des traumatismes 23 , mortalité $10 \%$ ), 627 ont subi un test d'alcoolémie à leur admission; $221(35 \%)$ présentaient un taux d'alcoolémie supérieur à $0 \mathrm{mmol} / \mathrm{L}$ et $189(30 \%)$ avaient un taux d'alcoolémie au-dessus de la limite permise de $17,4 \mathrm{mmol} / \mathrm{L}$. Le taux moyen des tests d'alcoolémie positifs était de $41,9 \mathrm{mmol} / \mathrm{L}$. Plus de $4 \%$ de ces cas avaient des antécédents d'alcoolisme. Les patients qui étaient sous l'effet de l'alcool ont davantage été victimes d'agressions ( $20 \%$ c. $9 \%$ ) ou d'accidents impliquant un véhicule $(10 \%$ c. $6 \%$; tous deux $p<0,05)$. La majorité des traumatismes ont été causés par des chutes $(37 \%)$ ou des accidents de la route $(33 \%)$. Dans l'ensemble, $17 \%$ des patients ont reçu un traitement prophylactique à la thiamine. Parmi les 221 patients qui présentaient un taux d'alcoolémie élevé, $44 \%$ ont reçu de la thiamine en prophylaxie. Parmi ceux qui présentaient des antécédents d'abus d'alcool, $77 \%$ ont reçu un traitement prophylactique à la thiamine.

Conclusion : Malgré le lien étroit entre abus d'alcool, traumatismes et EW, plus du tiers des patients n'ont subi aucun test d'alcoolémie. En outre, seule une minorité de patients intoxiqués ont reçu une prophylaxie adéquate contre l'EW. Compte tenu des 
risques faibles et des coûts peu élevés du test d'alcoolémie et de la prophylaxie par thiamine et des coûts élevés occasionnés par les épisodes de délire, il est essentiel d'instaurer des protocoles standard de prophylaxie.

elirium is associated with increased morbidity and mortality and length of stay in hospital (LOS) for severely injured patients. ${ }^{1}$ Many patient variables have been identified as risk factors for delirium, including older age, drug use, smoking, alcohol ingestion and poor nutrition. ${ }^{1}$ Similarly, the risk of delirium in surgical patients is known to be increased by nonpatient factors, such as the rapidity and severity of a physiologic insult. ${ }^{2}$

As a result, it is clear that most severely injured patients are at an increased risk for delirium given the acute, rapid and extensive nature of major trauma. This risk is further enhanced by the close association between chronic alcohol use and injury. More specifically, alcohol is the primary risk factor for both intentional and unintentional injuries in North America. ${ }^{1,2}$

A clinically important form of delirium associated with chronic alcohol use is Wernicke encephalopathy (WE), which manifests classically as the triad of mental status changes, opthalmoplegia and gait ataxia. ${ }^{3}$ Unfortunately, recent studies have identified this triad to be present in as few as $10 \%$ of all cases of WE. ${ }^{4}$ Although few randomized trials are available to guide dosing, scheduling or route of administration, thiamine is recommended for both the treatment and prevention of WE. Current recommendations for either prophylaxis or suspicion of $\mathrm{WE}$ are based primarily on clinical experience and observed successes with high physiologic levels (100 mg daily per os [PO], administered intravenously [IV] or intramuscularly [IM] until a regular diet is resumed). ${ }^{3,5}$

The primary goal of this study was therefore to audit the current practice of blood alcohol level (BAL) monitoring and thiamine prophylaxis at a level 1 trauma centre.

\section{Methods}

We retrospectively reviewed the cases of 1000 consecutive severely injured (injury severity score [ISS] > 12) patients admitted to the Foothills Medical Centre (FMC) in Calgary, Alta., between Mar. 1, 2009, and Dec. 30, 2009. The FMC is a Trauma Association of Canada-accredited level 1 trauma centre serving as the trauma referral facility for Southern Alberta, Southwestern Saskatchewan and Southeastern British Columbia. As a result, it treats all injuries among more than 2 million people; there are more than 1100 annual admissions of severely injured patients. We used the Alberta Trauma Registry to obtain patient data (i.e., age, sex, comorbidities, date of injury, mechanism of injury, LOS, intensive care unit [ICU] stay, injuries, ISS, discharge destination, operative procedures, blood alcohol level, presenting vital signs, death). Fidelity was ensured by additional searches of the Alberta Health Services electronic patient medical record. The pattern of thiamine use (i.e., dose, duration, timing of treatment) was obtained from this medical record. It should be noted that Canada's legal alcohol limit for operating a motor vehicle is $17.4 \mathrm{mmol} / \mathrm{L}(80 \mathrm{mg} / 100 \mathrm{~mL}){ }^{6}$ The University of Calgary Conjoint Health Research Ethics Board approved our study protocol.

\section{Statistical analysis}

We performed our data analyses using SPSS software version 19.0 (SPSS Inc.). Prior to analysis, we assessed the underlying distribution of all continuous variables using appropriate histograms. Normally or near-normally distributed variables are reported as means \pm standard deviation, and non-normally distributed variables are reported as medians with interquartile ranges (IQR). Comparisons were made using the $\chi^{2}$ test where appropriate. We considered results to be significant at $p<0.05$.

\section{RESULTS}

Among 1000 consecutive severely injured patients, demographic characteristics (Table 1), injuries (Table 2) and outcomes (Table 1) were consistent with data from previous years and admissions. Overall, 44 (4.4\%) patients had a documented history of alcohol abuse.

In total, 627 patients $(62.7 \%)$ had a BAL measured in the emergency department of the trauma centre. Of these patients, $221(35.2 \%)$ had a BAL greater than $0 \mathrm{mmol} / \mathrm{L}$, and $189(30.1 \%)$ had a BAL greater than $17.4 \mathrm{mmol} / \mathrm{L}$ $(80 \mathrm{mg} / 100 \mathrm{~mL})$. The mean BAL for those who tested positive on admission (221 patients) was $41.9 \pm 22.2 \mathrm{mmol} / \mathrm{L}$.

We assessed the mechanism of injury among the entire cohort as well as for the patients with elevated BAL on admission specifically, and these were compared using $\chi^{2}$ analysis (Table 2). We found a significant difference between

\begin{tabular}{lc}
$\begin{array}{l}\text { Table 1. Demographic and clinical characteristics of study } \\
\text { population }(\boldsymbol{n}=\mathbf{1 0 0 0})\end{array}$ & Mean \pm SD* \\
\hline Characteristic & $48.1870 \pm 21.5876$ \\
\hline Age, yr & $703(70)$ \\
\hline Male sex, no. (\%) & $22.9470 \pm 8.6600$ \\
\hline Injury severity score & $12.7060 \pm 24.3063$ \\
\hline Length of stay, d & $897(89.7)$ \\
\hline Survival to discharge, no. (\%) & $44(4.4)$ \\
\hline History of alcohol abuse, no. (\%) & \\
\hline $\begin{array}{l}\text { SD }=\text { standard deviation. } \\
* \text { Unless otherwise indicated. }\end{array}$
\end{tabular}




\begin{tabular}{|c|c|c|}
\hline \multirow[b]{2}{*}{ Mechanism of injury } & \multicolumn{2}{|c|}{ Group; no. (\%) } \\
\hline & $\begin{array}{c}\text { Total population, } \\
n=1000\end{array}$ & $\begin{array}{c}\text { Patients with } \\
\text { elevated BAL, } \\
\quad n=221\end{array}$ \\
\hline Motor vehicle crash & 327 (32.7) & 68 (30.8) \\
\hline Fall & 371 (37.1) & 67 (30.3) \\
\hline Bicycle accident & $25(2.5)$ & $5 \quad(2.3)$ \\
\hline Suicide attempt & $25(2.5)$ & $5 \quad(2.3)$ \\
\hline Assault & $92(9.2)$ & 44 (19.9) \\
\hline Pedestrian accident & $58 \quad(5.8)$ & $22(10.0)$ \\
\hline Explosion/fire/burn & 11 (1.1) & $2 \quad(0.9)$ \\
\hline Fall from animal/rodeo accident & $48(4.8)$ & $6 \quad(2.7)$ \\
\hline Other* & 39 (3.9) & $2 \quad(0.9)$ \\
\hline Gunshot wound & $4 \quad(0.4)$ & 0 \\
\hline \multicolumn{3}{|c|}{$\begin{array}{l}\text { BAL = blood alcohol level. } \\
{ }^{*} \text { Other includes struck by falling object, aircraft and watercraft accidents, sports- } \\
\text { related injuries, and machinery accidents. }\end{array}$} \\
\hline
\end{tabular}

injury patterns in the general trauma population and patients presenting with an elevated BAL. In particular, more patients were assaulted or hit by motor vehicles (both $p<0.05$ ) when intoxicated (Table 2). In addition, fewer animal-related mechanisms of injury were noted in intoxicated patients ( $p=0.043$; Table 2 ).

In total, 173 patients $(17.3 \%)$ received at least 1 dose of thiamine. On further examination, 98 of the $221 \mathrm{pa}-$ tients $(44.3 \%)$ with a BAL greater than $0 \mathrm{mmol} / \mathrm{L}$ received thiamine during their hospital stay. Unfortunately, only 89 of them (40.3\%) received their first dose of thiamine within the first 24 hours in hospital. Of the 44 patients with a documented history of alcohol abuse, $34(77.3 \%)$ received thiamine. Thiamine dosing was $100 \mathrm{mg}$ in all 173 patients who received this treatment. The precise route of administration was not available because it was typically documented as "IV/IM/PO" or "IV/IM." Finally, the duration of thiamine treatment was a mean of $5.4 \pm 9.37$ (range 1-66) days.

\section{Discussion}

Given high rates of associated alcohol abuse and subsequent malnutrition, the trauma population is at significant risk of being thiamine-deficient before injury and admission. Wernicke encephalopathy is a state of delirium that is most commonly related to thiamine deficiency as a result of either chronic alcohol abuse or other nutritionally deplete states. ${ }^{3}$ Thiamine is an important cofactor for enzymes involved in carbohydrate metabolism as part of the Krebs cycle. ${ }^{3}$ Because the half-life of thiamine stores in the human body is only 10-19 days, global deficiency can occur as quickly as within 1 month of nutritional deprivation. ${ }^{5}$ Low thiamine levels impair glucose metabolism and result in the cerebral and serum accumulation of lactate. The accumulation of these toxic metabolites in particular regions of the brain (e.g., thalami, mammillary bodies, tectal plate, periaqueductal area) induces damage and results in the symptoms associated with WE. ${ }^{7,8}$ It has been speculated that these areas of the brain are characterized by intense thiamine metabolism, making them more susceptible to thiamine deficiency. ${ }^{9}$

Despite current recommendations for the treatment and prophylaxis of WE $(100 \mathrm{mg}$ of thiamine IV/IM/PO per day until a regular diet is resumed), ${ }^{3,5}$ only $17.3 \%$ of all injured patients at our centre received at least a single dose of thiamine. When limited to patients with an elevated BAL on admission, coverage increased to only $44.3 \%$. Among the highest risk cohort (patients with a documented history of alcohol abuse), nearly $23 \%$ of patients did not receive thiamine prophylaxis. Although these results are comparable to a prior study from Denver $(47 \%$ of 153 intoxicated emergency department patients received thiamine prophylaxis), ${ }^{2}$ our low rate of successful thiamine coverage represents a clinically important failure in our care of patients at risk for delirium. Taken together, these studies suggest that without a standard protocol, BAL monitoring and thiamine prophylaxis is easily overlooked in the early care of trauma patients. Given the rarity of adverse events associated with thiamine administration (1 in 250000 patients may experience anaphylaxis) ${ }^{3,10}$ and the reality that up to $25 \%$ of cases of untreated WE lead to death, the importance of prophylaxis becomes clear. Furthermore, Korsakoff syndrome, a persistent state of memory impairment typically requiring institutionalization, will also develop in up to $85 \%$ of the patients who survive WE. Considering that thiamine rapidly improves ataxia and opthalmoplegia within hours of administration as well as global confusion within hours to days of treatment, the utility of prophylaxis and treatment is obvious.,11

Although it appeared that all patients in our study who received thiamine were given the correct dose $(100 \mathrm{mg})$, an evaluation of the specific route of administration was not possible owing to poor electronic documentation. Route of administration is a relevant economic variable: the costs listed in the Alberta Health Services Drug Formulary are $\$ 0.97 /$ dose for an IV injection compared with $\$ 0.05 /$ dose for a pill. The mean duration of treatment was 5.4 (range 1-66) days. Although we would like to assume that the duration of treatment was clinically correct, the specific reasons for stopping thiamine prophylaxis were not evident in the electronic record. Presumably therapy was stopped owing to the resumption of a normal diet and/or discharge from the hospital.

Although testing BAL at the time of admission would not detect chronic alcohol abusers if they had not recently consumed alcohol, it would be helpful in predicting which patients may require thiamine prophylaxis or enter withdrawal. Furthermore, high BAL on admission may indicate that a patient has developed a tolerance to alcohol owing to chronic use. Given that only $62.7 \%$ of our severely injured patients underwent BAL testing, with 35\% showing recent 
ingestion of alcohol, it is clear that an improvement in screening is needed.

Despite data suggesting that WE is rare $(0.06 \%-$ $0.13 \%)$, postmortem studies have recently reported rates as high as $2.8 \%$ in injured patients. ${ }^{12,13}$ This has been emphasized in patients with major injuries (ISS 16-31) who display severe thiamine deficiency within the first week of injury despite routine nutritional support. ${ }^{14}$ It also compares to healthy controls who manifest only moderate deficiency for up to 21 days after nutritional deprivation. ${ }^{14}$ This suggests that low thiamine levels result from a combination of poor nutritional intake and increased catabolism in critically ill patients. Furthermore, if one uses the classic triad of mental status changes, opthalmoplegia and gait ataxia as a diagnostic indicator for WE, up to $90 \%$ of cases may be missed. ${ }^{4}$ Given that altered mental status is the most common finding in patients wtih WE, it must always remain high on any differential diagnosis for postadmission delirium. ${ }^{3,4}$

\section{Conclusion}

Preventing delirium should be a priority in the care of all injured patients. Standard testing of BAL at the time of admission could assist in guiding both the prophylaxis of alcohol withdrawal and the need for thiamine prophylaxis against WE. Furthermore, implementation of a protocolized thiamine prophylaxis program aimed at treating all patients with an elevated BAL on admission or with a history of alcohol abuse should be considered in all emergency departments and level 1 trauma centres. By implementing this as a quality improvement manoeuvre, we hope to improve the rate of adequate prophylaxis for WE.

Competing interests: A.W. Kirkpatrick declares travel assistance (reimbursement) from the Lifecell Corporation. No other competing interests declared.

Contributors: C. Blackmore, J.-F. Ouellet and C.G. Ball designed the study. C. Blackmore, and C.G. Ball acquired and analyzed the data, which were also analyzed by D. Niven and A.W. Kirkpatrick. C. Blackmore and C.G. Ball wrote the article, which all authors reviewed and approved for publication.

\section{References}

1. Noimark D. Predicting the onset of delirium in the post-operative patient. Age Ageing 2009;38:368-73.

2. Lowenstein SR, Weissberg MP, Terry D. Alcohol intoxication, injuries, and dangerous behaviors, and the revolving emergency department door. F Trauma 1990;30:1252-8.

3. Donnino MW, Vega J, Miller J, et al. Myths and misconceptions of Wernicke's encephalopathy: what every emergency physician should know. Ann Emerg Med 2007;50:715-21.

4. Torvik A. Wernicke's encephalopathy - prevalence and clinical spectrum. Alcohol Alcohol Suppl 1991;1:381-4.

5. Fuentebella J, Kerner JA. Refeeding syndrome. Pediatr Clin North Am 2009;56:1201-10.

6. Government of Canada. Criminal Code (R.S.C. 1985, c. C-46). Available: http://laws-lois.justice.gc.ca/eng/acts/c-46/page-127.html (accessed 2012 Jan. 20).

7. Butterworth RF, Kril JJ, Harper CG. Thiamine-dependent enzyme changes in the brains of alcoholics: relationship to the WernickeKorsakoff syndrome. Alcohol Clin Exp Res 1993;17:1084-8.

8. Hazell AS, Todd KG, Butterworth RF. Mechanisms of neuronal cell death in Wernicke's encephalopathy. Metab Brain Dis 1998;13:97-122.

9. Zuccoli G, Pipitone N. Neuroimaging findings in acute Wernicke's encephalopathy: review of the literature. A7R Am 7 Roentgenol 2009; 192:501-8.

10. Thomson AD, Cook CC. Parenteral thiamine and Wernicke's encephalopathy: the balance of risks and perception of concern. Alcobol Alcobol 1997;32:207-9.

11. Day E, Bentham P, Callaghan R, et al. Thiamine for Wernicke-Korsakoff syndrome in people at risk from alcohol abuse. Cochrane Database Syst Rev 2004;1:CD004033.

12. Onishi H, Sugimasa Y, Kawanishi C, et al. Wernicke encephalopathy presented in the form of postoperative delirium in a patient with hepatocellular carcinoma and liver cirrhosis: a case report and review of the literature. Palliat Support Care 2005;3:337-40.

13. Harper C, Gold J, Rodriguez M, et al. The prevalence of the WernickeKorsakoff syndrome in Sydney, Australia: a prospective necropsy study. 7 Neurol Neurosurg Psychiatry 1989;52:282-5.

14. McConachie I, Haskew A. Thiamine status after major trauma. Intensive Care Med 1988;14:628-31. 